\title{
Isolation and Characterization of Human Suture Mesenchymal Stem Cells In Vitro
}

\author{
Liangliang Kong, Yuan Wang, Yi Ji, Jianbing Chen, Jie Cui, Weimin Shen \\ Department of Plastic Surgery, Children's Hospital of Nanjing Medical University, Nanjing, China
}

Background and Objectives: Cranial sutures play a critical role in adjustment of skull development and brain growth. Premature fusion of cranial sutures leads to craniosynostosis. The aim of the current study was to culture and characterize human cranial suture mesenchymal cells in vitro.

Methods: The residual skull tissues, containing synostosed or contralateral suture from three boys with right coronal suture synostosis, were used to isolate the suture mesenchymal cells. Then, flow cytometry and multilineage differentiation were performed to identify the typical mesenchymal stem cell (MSC) properties. Finally, we used quantitative real-time polymerase chain reaction (RT-PCR) to detect the mRNA expression of osteogenesis and stemness related genes.

Results: After 3 to 5 days in culture, the cells migrated from the tissue explants and proliferated parallelly or spirally. These cells expressed typical MSC markers, CD73, CD90, CD105, and could give rises to osteocytes, adipocytes and chondrocytes. RT-PCR showed relatively higher levels of Runx2, osteocalcin and FGF2 in the fused suture MSCs than in the normal cells. However, BMP3, the only protein of BMP family that inhibits osteogenesis, reduced in synostosed suture derived cells. The expression of effector genes remaining cell stemness, including Bmil, Glil and Axin2, decreased in the cells migrated from the affected cranial sutures.

Conclusions: The MSCs from prematurely occlusive sutures overexpressed osteogenic related genes and down-regulated stemness-related genes, which may further accelerate the osteogenic differentiation and suppress the self-renewal of stem cells leading to craniosynostosis.

Keywords: Cranial suture, Craniosynostosis, Human, Mesenchyme stem cell

\section{Introduction}

The human skull is made up of multiple bones, which

Received: February 1, 2020, Revised: May 31, 2020,

Accepted: June 6, 2020, Published online: June 30, 2020

Correspondence to Weimin Shen

Department of Plastic Surgery, Children's Hospital of Nanjing Medical University, 72 Guangzhou Road, Nanjing 210008, China Tel: +86-25-83117584, Fax: +86-25-52862934

E-mail: swmswmswm@sina.com

(c) This is an open-access article distributed under the terms of the Creative Commons Attribution Non-Commercial License (http://creativecommons.org/ licenses/by-nc/4.0/), which permits unrestricted non-commercial use, distribution, and reproduction in any medium, provided the original work is properly cited.

Copyright (c) 2020 by the Korean Society for Stem Cell Research is connected by fibrous connective tissue, the cranial sutures, consisting of fibrous tissues, two osteoblastic fronts, suture mesenchymal cells between them, overlying periosteum and underlying dura membrane (1). These sutures need to remain patent in the preliminary stages of development, allowing the skull deformation during birth and expansion during brain growth, and play a pivotal role in adjusting the balance between proliferation and differentiation of mesenchymal cells (2). One or more cranial sutures premature fusion causes craniosynostosis, a severe congenital craniofacial abnormality which occurs in about $1: 2,500$ live births and may result in skull deformities and asymmetry, increased intracranial pressure, evenly neuro and mental retardation $(3,4)$. The basic treatment for these patients is surgical reconstruction of the artificial 
cranial sutures and re-shaping of the calvarial bones. Although it is temporarily beneficial to the rapid development of brain and improves the craniofacial appearance, the incidence of post-operative complications and recurrence remain high $(5,6)$. In addition, the natural suture tissue is usually discarded as surgical waste during the surgical procedure (7).

In mice, the sagittal suture remain patent throughout the life, while the posterior frontal (PF) suture, analogous to metopic suture in humans, gradually fuses within $2 \sim 3$ weeks after birth (8). Xu et al. (9), firstly isolated and cultured cranial sutures derived mesenchymal cells in mice, and found that the expression of fibroblast growth factor 2 (FGF2) in PF is significantly higher than in the sagittal suture cells. Moreover, BMP3 is gradually decreased during the PF suture fusion, and administering FGF2 induced calvarial osteogenesis with the downregulation of BMP3 (10). The underlying mechanism of suture biology leading to craniosynostosis should be carefully understood. More key molecules regulating differentiation and self-renewal of suture mesenchymal stem cells (MSCs) have been found. The suture Glil ${ }^{+}$MSCs could differentiate into osteogenic cells, periosteum and dura in vivo and in vitro. Further, elimination of these MSCs leads to craniosynostosis, thereby impeding the growth of skull vault (11). Another important molecule, Axin2 is expressed in all calvarial sutures except the PF suture, and the stem cell properties of Axin $2^{+}$cells maintained the middle of the suture and continually gave rise to the mature cell types (12). However, the MSC properties of human suture mesenchymal cells are still unclear.

In this study, we initially isolated and cultured the fused and contralateral suture mesenchymal cells and identified their properties using flow cytometry and multilineage differentiation. At last, we used quantitative real-time polymerase chain reaction (RT-PCR) to explore the mRNA expression of osteogenic and stemness related genes in these two MSCs.

\section{Materials and Methods}

\section{Patients}

Three boys (aged 4 to 10 months) suffering from unilateral coronal synostosis were performed cranium osteotomy. All patients had right coronal synostosis, confirmed by the three-dimensional computed tomographic scan and $\mathrm{H} \& \mathrm{E}$ stain (Fig. 1A C). The residual skull tissues containing of fused or contralateral cranial suture were used to isolate the suture derived cells. The informed consent for medical research was approved and signed by the patient's parents.
All experiments were approved by the Children's Hospital of Nanjing Medical University Ethics Committee (ID: 201705097-1).

\section{Isolation and culture of suture mesenchymal cells}

The suture mesenchyme cells were isolated from human residual skull tissues as previously described (9). Briefly, the tissues, separated from the underlying dura mater and overlying pericranium in the operation, were transferred to the lab in phosphate buffered saline (PBS, Invitrogen, CA, USA) and cultured in medium containing alphaModified Eagle Medium ( $\alpha$-MEM, Invitrogen, CA, USA) supplemented with $10 \%$ fetal bovine serum (FBS, Invitrogen, CA, USA), penicillin (100 units/ml), and streptomycin $(100 \mathrm{mg} / \mathrm{ml})$ at $37^{\circ} \mathrm{C}$ in an atmosphere of $5 \% \mathrm{CO}_{2}$ (Fig. 1D). After 3 to 5 days in culture, the suture-derived mesenchymal cells migrated from the explant tissues. Medium was changed every 3 days. The cells of fewer than 2 to 3 passages were used for all experiments and stained with $0.25 \%$ crystal violet blue showing cytoskeletal structure.

\section{Real-time PCR}

Total RNA was isolated from cultured cells with the TRIzol reagent (Invitrogen, CA, USA) and reverse-transcribed with a reaction mixture. Quantitative real-time PCR (qPCR) analysis was performed using the SYBR Green qPCR Master Mix (Applied Biosystems, ABI, CA, USA) and Applied Biosystems 7500 real-time PCR system (ABI, CA, USA). The expression data was normalized to the expression of GAPDH. The primers used for SYBR Green qPCR are shown in Table 1. The comparative threshold cycle $(\mathrm{Ct})$ method was used to measure the relative changes in expression; $2^{-\Delta \Delta C t}$ represents the fold change of expression, as previously described (13).

\section{Flow cytometry}

The cells were centrifuged and resuspended in the prepared buffer and stained with PerCP-Cy5.5 conjugated anti-CD105, APC conjugated anti-CD73, FITC conjugated anti-CD90 and PE conjugated anti-negative cocktail (CD45/ CD34/CD11b/CD19/HLA-DR) according to the manufacturer's instructions (BD Biosciences, CA, USA). Stained cells were washed twice with PBS and performed on BD FACSCalibur (BD Biosciences, CA, USA). The compensation controls and irrelevant $\mathrm{IgG}$ isotype controls were simultaneously used.

\section{Multilineage differentiation}

For osteogenic differentiation cells were firstly grown to 


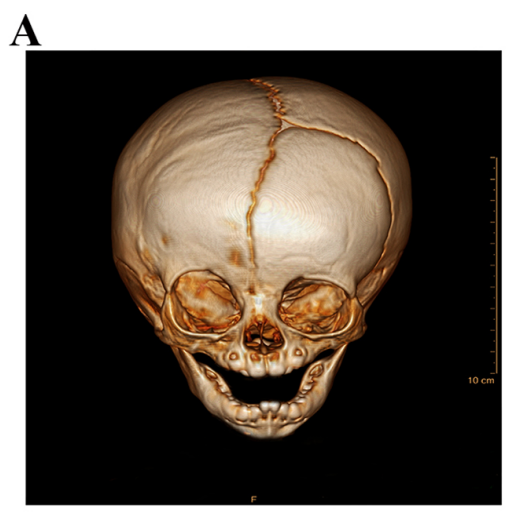

Patient 1

B

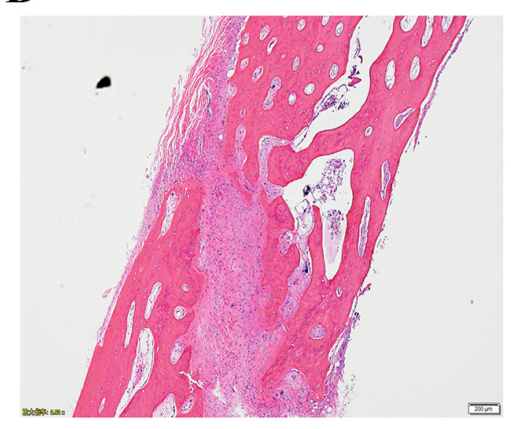

$\mathbf{E}$

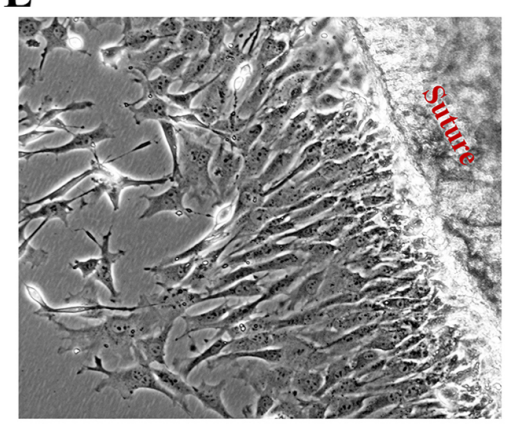

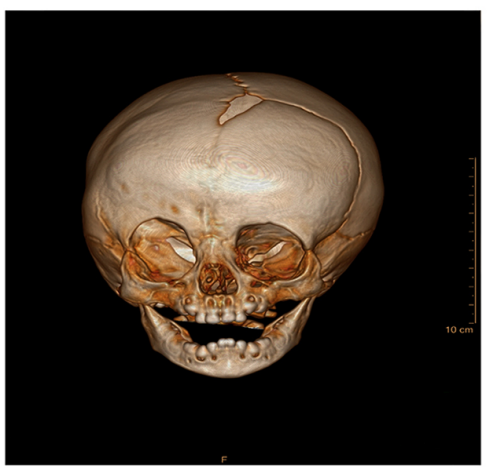

Patient 2

C

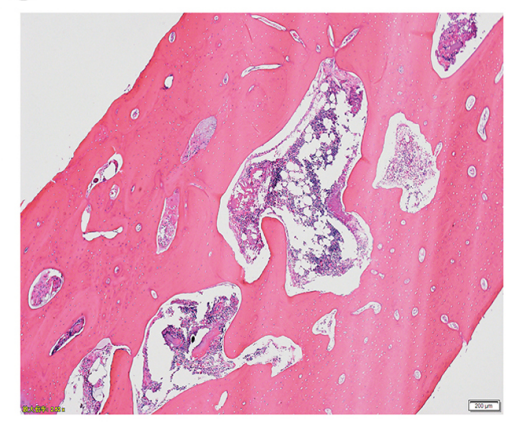

F

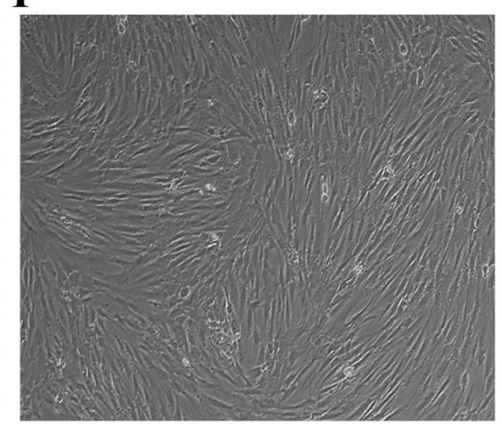

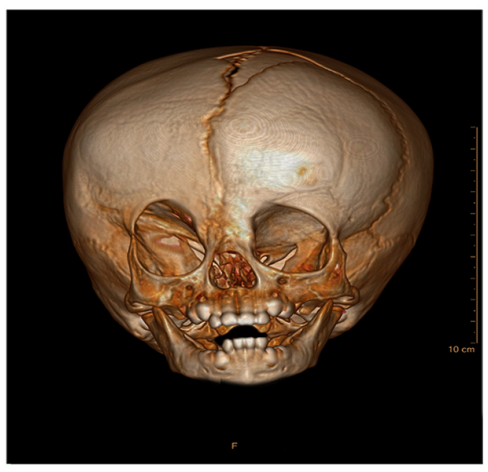

Patient 3

D

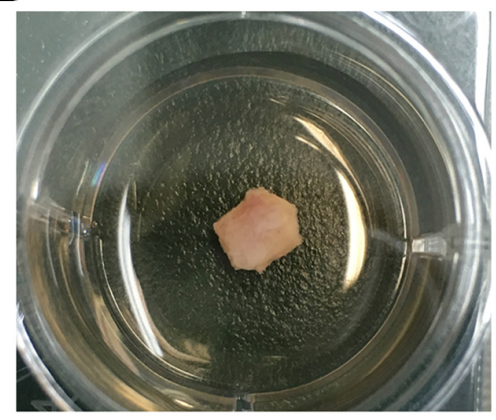

G

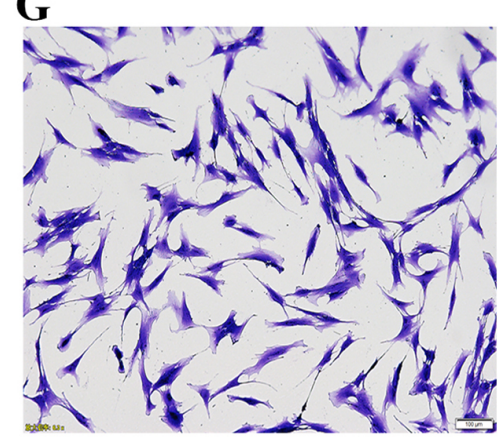

Fig. 1. Isolation and culture of suture mesenchymal stem cells. (A) Craniofacial computed tomographic scan with three-dimensional reconstruction of three patients before operation showed typically right coronal suture fusion. Representative H\&E staining of contralateral patent suture (B) and prematurely fused suture (C). (D) The tissues, containing fused or contralateral cranial suture, in the culture dishes. (E) The cells were migrating from the cranial suture tissue. $(F, G)$ Inverted microscopic view of suture mesenchymal cells exhibiting almost homogeneous spindle morphology and stained with $0.25 \%$ crystal violet blue.

$100 \%$ confluence, and then cultured with medium containing $\alpha$-MEM with $10 \% \mathrm{FBS}$, ascorbate, $\beta$-glycerophosphate and dexamethasone (Cyagen Biosciences, Jiangsu, China) for nine days. Medium was changed every 3 days. Alizarin red staining was performed and recorded using an inverted microscope (Olympus, Tokyo, Japan). In addition, mRNA expression of Runx2 and osteocalcin (OCN) was analyzed with qPCR. To assess adipogenic differentiation cells were cultured at $100 \%$ confluence for $2 \sim 3$ weeks in $\alpha$-MEM containing 10\% FBS, L-glutamine, insulin, isobutylmethylxanthine, rosiglitazone and dexamethasone (Cyagen Biosciences, Jiangsu, China). Medium was changed every $2 \sim 3$ days and then Oil red staining was performed. For chondrogenic differentiation, $3-4 \times 10^{5}$ suture mesenchyme cells were cultured as a pellet at the bottom of a $15 \mathrm{ml}$ aseptic tube in $0.5 \mathrm{ml} \alpha$-MEM medium supplemented TGF- $\beta 3$, dexamethasone, ascorbate, sodium pyruvate and proline (Cyagen Biosciences, Jiangsu, 
Table 1. Sequences of RT-PCR primers

\begin{tabular}{|c|c|c|c|}
\hline Gene name & & Sequences & Size (bp) \\
\hline \multirow[t]{2}{*}{ Runx2 } & Forward: & 5'-САCСТTGACCATAACCGTCTTC-3' & 196 \\
\hline & Reverse: & 5'-CGGGACACCTACTCTCATACTG-3' & \\
\hline \multirow[t]{2}{*}{$\mathrm{OCN}$} & Forward: & 5'-GACTGTGACGAGTTGGCTGA-3' & 233 \\
\hline & Reverse: & 5'-GCCCACAGATTCCTCTTCTG-3' & \\
\hline \multirow[t]{2}{*}{ BMP3 } & Forward: & 5'-TCAGGCCGTAGATCATTGTTG-3' & 215 \\
\hline & Reverse: & 5'-AGGTAACACAGTGCCTTTCACA-3' & \\
\hline \multirow[t]{2}{*}{ FGF2 } & Forward: & 5'-AAGACCAACCTGGTGAAACC-3' & 151 \\
\hline & Reverse: & 5'-TTATGGCTCACTGCAАCCTT-3' & \\
\hline \multirow[t]{2}{*}{ FGFR2 } & Forward: & 5'-GGATAACAACACGССТСТCTTC-3' & 155 \\
\hline & Reverse: & 5'-CATGACCACTTGCCCAAAG-3' & \\
\hline \multirow[t]{2}{*}{ FGFR3 } & Forward: & 5'-GGAGGTGATTCCAGTGAAGATA-3' & 150 \\
\hline & Reverse: & 5'-TGGGACACACAGCAATTAGAAG-3' & \\
\hline \multirow[t]{2}{*}{ Bmi1 } & Forward: & 5'-GCTGCTCTTTCCGGGATT-3' & 184 \\
\hline & Reverse: & 5'-TGCTGGTCTCCAGGTAACG-3' & \\
\hline \multirow[t]{2}{*}{ Lef1 } & Forward: & 5'-CCTTGGTGAACGAGTCTGAA-3' & 237 \\
\hline & Reverse: & 5'-TGGGTGGAGAAAGAGATCCA-3' & \\
\hline \multirow[t]{2}{*}{ Gli1 } & Forward: & 5'-AGGAGTTCGTGTGCCACTG-3' & 239 \\
\hline & Reverse: & 5'-GGCATTGCTGAAGGCTTTAC-3' & \\
\hline \multirow[t]{2}{*}{ Nanog } & Forward: & 5'-CACTACGACCCAGGCTTCAT-3' & 234 \\
\hline & Reverse: & 5'-CCACAGCCACATCTGTAАCTTC-3' & \\
\hline \multirow[t]{2}{*}{ Axin2 } & Forward: & 5'-TTGAGCTAGGAGTGCGTTCA-3' & 206 \\
\hline & Reverse: & 5'-CAACATGGTCAACCCTCAAG-3' & \\
\hline \multirow[t]{2}{*}{ GAPDH } & Forward: & 5'-CAACATGGTCAACCCTCAAG-3' & 197 \\
\hline & Reverse: & 5'-CAACATGGTCAACCCTCAAG-3' & \\
\hline
\end{tabular}

China) and changed every 3 days. After 21 days culture, the cell microsphere was formalin-fixed and paraffin-embedded and then sectioned at $4 \mathrm{~mm}$, stained with Alcian blue.

\section{Colony formation assay}

Both cell types of 2 passages were cultured in 6-well plates at a density of 5,000 cells per well as previously described (14). Culture media was changed every five days. After 3 weeks, cells were stained with $0.4 \%$ crystal violet (Beyotime Biotech, Jiangsu, China). The colonies $>2 \mathrm{~mm}$ was counted and the number of colonies per well was calculated. Each measurement was performed at least 3 times.

\section{Statistical analysis}

Statistical analysis was performed using SPSS software, version 19.0 (SPSS Inc, Ill, USA). Results are expressed as mean values and standard deviations. Parameters were analyzed by Student's t-test. For the above parameters, $p<$ 0.05 was considered statistically significant.

\section{Results}

\section{Morphology and identification of suture mesenchymal cells}

As shown in Fig. $1 E \sim G$, the cells, migrating from the cranial suture tissue, exhibited homogeneous spindle morphologies when stained with $0.25 \%$ crystal violet blue and proliferated parallelly or spirally like the typical MSCs. To identify whether these cells in the suture mesenchyme are typical MSCs, Flow cytometry was performed and indicated that these cells highly expressed MSC markers, CD73, CD90, CD105, but not MSC negative cocktail, such as CD34, CD11b, CD45 and HLA-DR (Fig. 2A). Further experiments showed that they are capable of osteogenic, adipogenic and chondrogenic differentiation (Fig. $2 B \sim D$ ).

\section{Expression of osteogenic related genes in suture MSCs}

To assay the osteogenic potential that vary between the synostosed and patent suture, we firstly performed osteogenic differentiation test and found that both mesenchymal cells can give rises to osteocytes, established by alizarin red stain and mRNA expression of marked genes, Runx2 and $\mathrm{OCN}$ (Fig. 3A C). As predicted, Runx2 and OCN were expressed significantly higher in the affected suture 
A
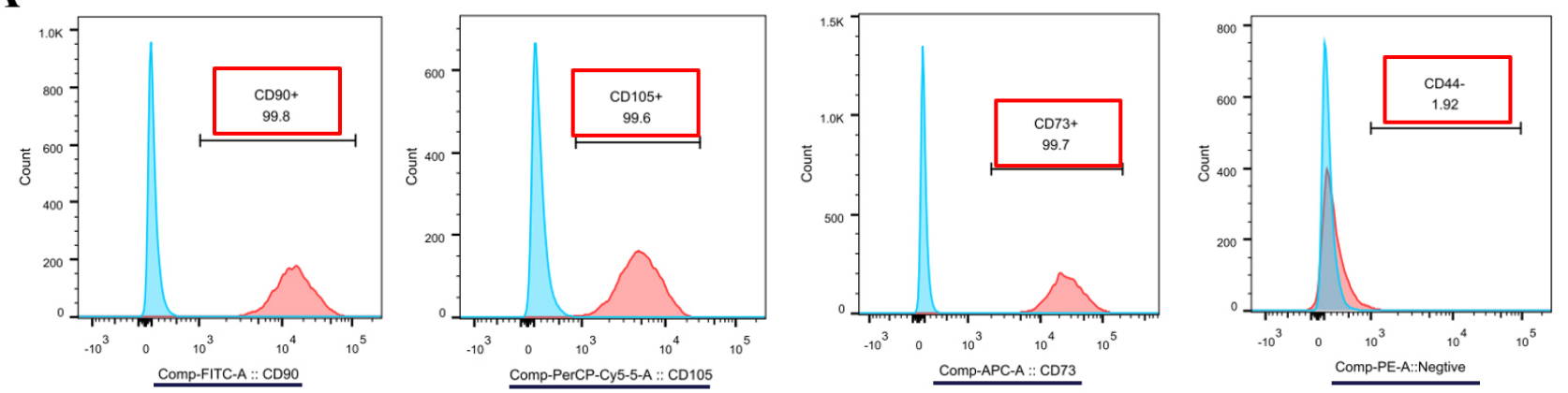

B
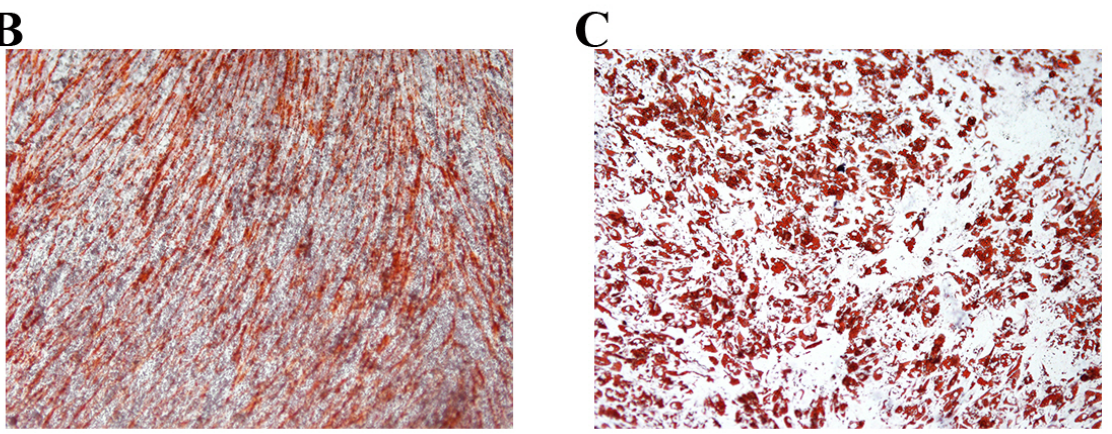

D

Fig. 2. Identification of suture mesenchymal stem cells. (A) FACS analysis of mesenchymal stem cells migrated from the explanted sutures. Alizarin red (B), Oil red (C) and Alcian blue (D) staining indicates that the suture mesenchymal cells can undergo osteogenic, adipogenic and chondrogenic differentiation.

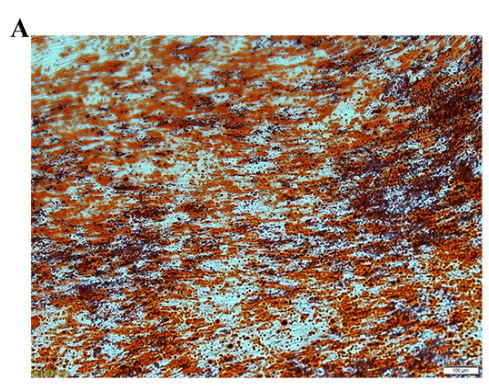

Normal

B

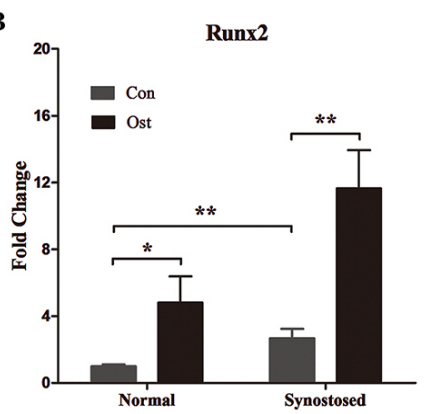

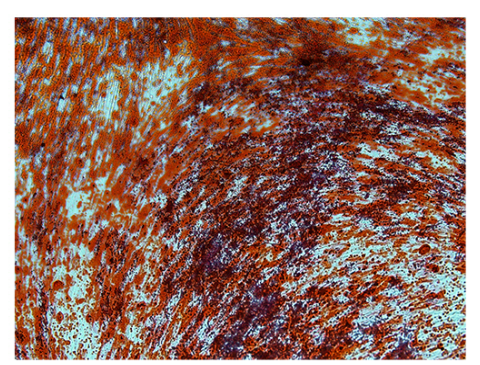

Synostosed

C

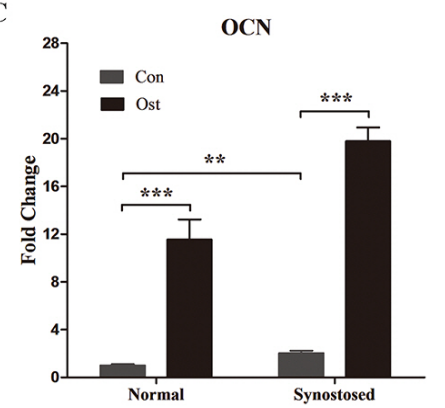

D

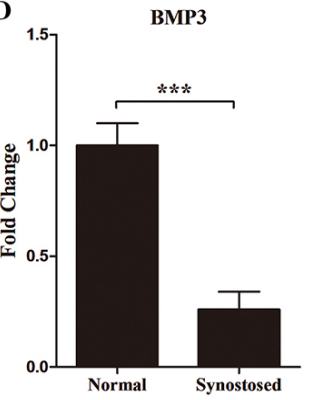

F

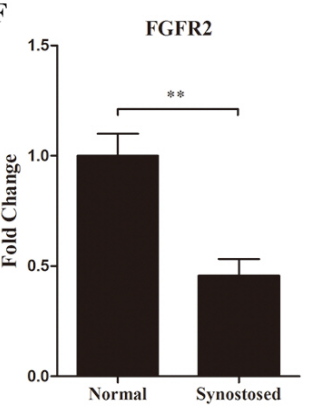

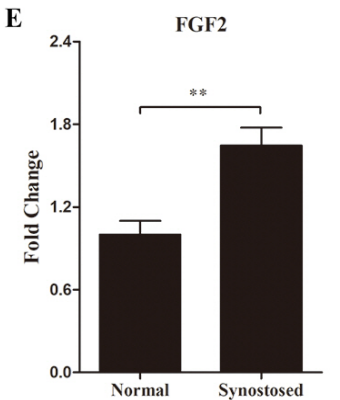

G

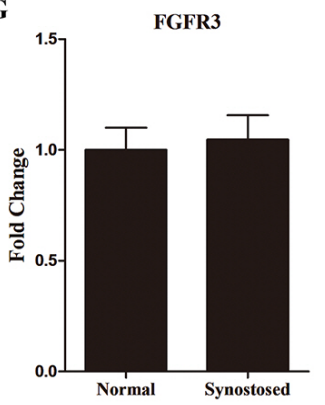

Fig. 3. Expression of osteogenic phenotypic genes and FGFR family genes in suture cells. (A-C) Osteogenic differentiation in the mesenchymal stem cells, from normal patent sutures (Normal group) or prematurely synostosed sutures (Synostosed group), was tested. Con, control group without osteogenic induction; Ost, osteogenic differentiation group with osteogenic induction. (A) Representative pictures of Alizarin Red $S$ staining. Both Cells were cultured with osteogenic induction media for six days. (B, C) mRNA levels of Runx2 and OCN by RT-PCR analysis. (D G) RT-PCR analysis of BMP3, FGF2, FGFR2 and FGFR3 in normal and synostosed sutures-derived mesenchymal cells. Results are mean \pm SD. ${ }^{*} p<0.05, * * p<0.01$, and ${ }^{* * *} p<0.001$ versus normal cells. OCN, osteocalcin. 


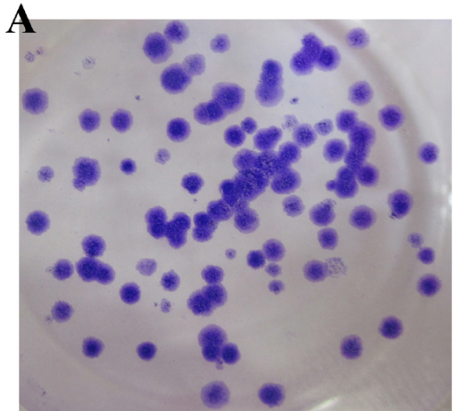

Normal

D

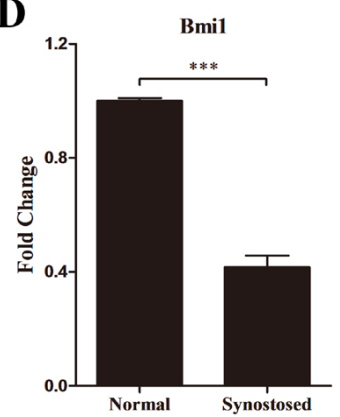

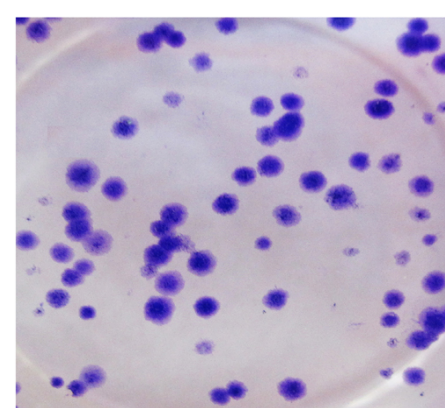

Synostosed

$\mathbf{E}$

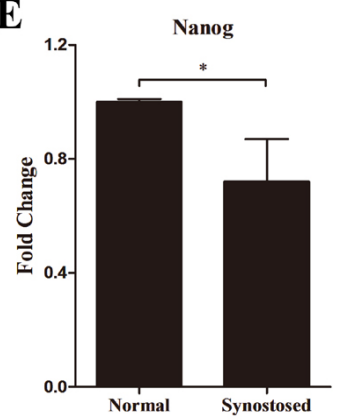

B

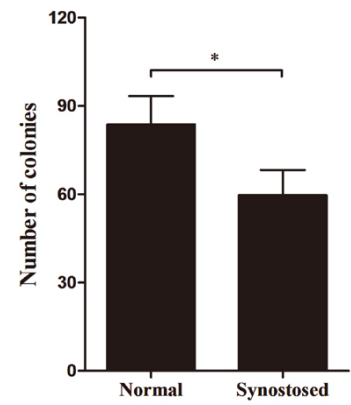

F

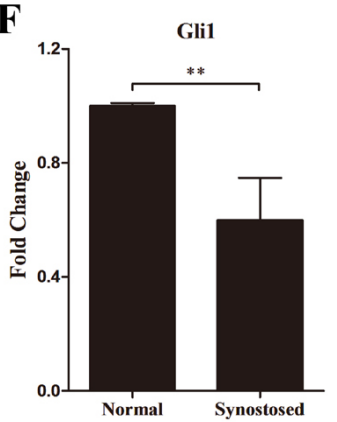

$\mathbf{C}$

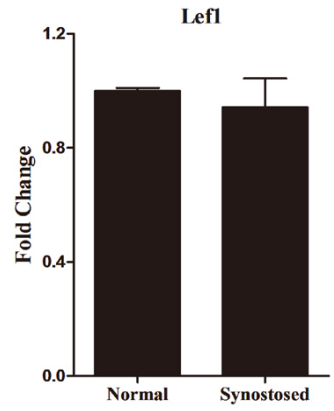

G

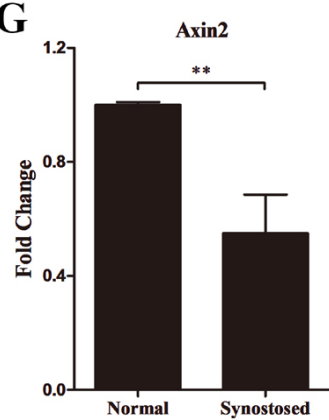

Fig. 4. Expression of stemness-related genes in suture cells. (A, B) Colony formation of two mesenchymal cell types and the number of colonies per well was calculated. $(C \sim G)$ mRNA levels of Lef1, Bmi1, Nanog, Gli1 and Axin2 in normal and synostosed sutures-derived mesenchymal cells using quantitative PCR. Results are mean \pm SD. ${ }^{*} p<0.05,{ }^{* *} p<0.01$, and ${ }^{* * *} \mathrm{p}<0.001$ versus normal cells. Normal, normal patent sutures derived cells and Synostosed, prematurely synostosed sutures derived cells.

derived MSCs than in the normal suture cells (Fig. 3B and 3C). In contrast, the expression of BMP3 was notably decreased in premature fused suture cells compared with normal cells (Fig. 3D).

Fibroblast growth factors (FGF) and their receptors (FGFR) have been confirmed to have a pronounced role in the osteogenic differentiation and skull growth. Gainof-functional mutations of FGFR2 and FGFR3 have been linked to diverse types of syndromic craniosynostosis (15, 16). We therefore wondered whether the level of FGF signaling gene altered the human suture MSCs following premature fusion. Gene expression of FGF2 elevated conspicuously in MSCs, separated from the synostosed coronal suture (Fig. 3E). However, the level of FGFR2 decreased in the affected suture MSCs compared to the contralateral cells (Fig. 3F). The FGFR3 mRNA level remained unchanged (Fig. 3G).

\section{Stemness-related genes expression in suture MSCs}

Stem cells regulate self-renewal to maintain stemness and replenish the stem cells niche after differentiation through proliferating, repressing differentiation, and reducing apoptosis (17). The colony formation assay revealed that the infused suture MSCs reduced colony for- mation relative to normal cells (Fig. 4A and 4B). Multiple signaling pathways, such as Shh, Notch, Wnt, and the polycomb group genes have been reported to maintain stem cell properties (18). To explore the stemness of the suture-derived MSCs, qPCR analyses were performed to detect the expression of effector genes in the above-mentioned pathways. As shown in Fig. 4C, similar expression pattern of Lefl was found in the two populations. However, we observed that the mRNA expression of Bmil markedly reduced in the synostosed suture MSCs compared with normal cells (Fig. 4D). Like this, Nanog, Glil, Axin2 showed conspicuously lower expression levels in the affected suture cells (Fig. $4 \mathrm{E} \sim \mathrm{G}$ ).

\section{Discussion}

Craniosynostosis was first named by Otto (19) in 1830 and described the premature fusion of one or more cranial sutures. Following rapid growth of the brain in turn resulted in high intracranial pressure, craniofacial asymmetry, especially a variety of neurological disorders affecting vision, hearing and intelligence (4). The primary treatment for craniosynostosis is cranial osteotomy. However, the adverse reactions such as trauma and hemorrhage dur- 
ing the operation were huge, moreover, the incidence of post-operative complications and recurrence remain high $(5,6)$. Thus, we need to explore the exact mechanism regulating premature closure of cranial sutures and more appropriate way of surgical or pharmacological methods. In recent reports, the stemness and pluripotency of suture mesenchymal cells were confirmed in several mice models in vivo and in vitro $(11,12,20)$. We thus hypothesized that the suture MSCs may play a vital role in craniosynostosis. In this study, we have isolated and cultured the human suture mesenchymal cells of the patients with right coronal synostosis and firstly identified these cells as typical MSCs. Moreover, we demonstrated elevated expression levels of osteogenic phenotypic genes and the decrease in the expression of the stemness-related genes in the synostosed suture derived MSCs.

Stem cells in the cranial sutures act as key factors in the development by differentiating directly into osteoblasts, which then form calvarial bones (21). When detecting the expression of the osteogenic related genes in suture derived MSCs, we found that the levels of Runx2 and OCN are markedly higher in the right coronal suture MSCs than in the contralateral cells. Meanwhile, the Alizarin red staining also showed that the prematurely fused suture MSCs had stronger osteogenic differentiation ability. Runx2, as a transcription factor, regulates osteogenic differentiation by regulating osteoblast related genes, such as OCN, alkaline phosphatase, collagen type I and bone sialoprotein (22). Moreover, overexpression of Runx2 increased osteogenic differentiation and accelerated suture closure in many models of craniosynostosis (23, 24), implying an important effect in the cranial suture biology, and our current data coincides with this hypothesis. However, the expression of BMP3 compared to normal cells was significantly reduced in the prematurely fused suture MSCs. This result was supported by a recent finding that downregulating BMP3 expression with suture closure over time which suggested that this gene acts on the suture patency (10).

The mutations in FGFR2 and FGFR3 are well-established in syndromic craniosynostosis via ligand-independent constitutive activation of receptors $(15,16)$. In this study, we found that the mRNA levels of FGFR2 were decreased in synostosed suture cells, but the levels of FGFR3 remained unchanged in the mesenchymal stem cells. This might be due to the localized expression of FGFR to specific regions of the cranial sutures (25). In addition, FGF2 is abundantly higher expressed in fused suture MSC, coinciding with previous report (9). Over-expression of FGF-2 induced the normally patent coronal suture pathologic fu- sion, whereas in vivo abrogation of FGF-2/FGFR signaling led to aberrant suture patency in mice (26).

MSCs are characterized by the activity of self-renewability and has potential to differentiate into multiple cell lineages, including osteoblasts, chondrocytes, adipocytes, and cardiomyocytes $(27,28)$. Suture-derived mesenchymal cells in our experiment highly express in MSC markers, CD73, CD90, CD105, but not CD34, CD11b, CD45 and HLA-DR and can similarly give rise to osteocytes, adipocytes and chondrocytes, established by specific stain respectively. The other central question is to explore the stemness properties of suture MSCs. To remain stemness, these cells must proliferate, but repress the differentiation and reduce apoptosis (28). We performed the colony formation assay and found that the affected suture MSCs reduced colony formation compared to normal cells. We further found that the mRNA levels of Bmil significantly reduced in synostosed suture MSCs. Bmil, the polycombgroup transcriptional repressor, which is confirmed as a key regulator to regulate the stem cell self-renewability and proliferation in several cell types (29). Bmil knockout mice experienced skeletal defects, reduced post-natal growth and density in the cerebellum and neural layers (30). Biehs et al. (31), showed that Bmil is expressed in the incisor stem cells and regulates stem cell maintenance and enamel production via repressing Hox genes. In addition, the expression of Nanog was also decreased in the premature fused suture MSCs. It is well verified that Nanog expresses in the embryonic stem cells (ESCs) to regulate ESCs self-renewal and maintenance (32, 33). Moreover, Nanog can target the Bmil promoter to directly transactivate and regulate Bmil (33). We also observed that Gli1 and Axin2 showed markedly lower levels in the synostosed suture MSCs than in the normal cells. However, the expression of Lef1 demonstrated no difference in both groups. Glil is specifically expressed within the suture mesenchymal stem cells and ablation of the $\mathrm{Glil}^{+}$stem cells which resulted in the cranial suture fusion in mice model (11). A recent report showed that Axin2 positive suture mesenchymal cells are capable of long-term self-renewal during development and maintenance (12). They also found that Axin2 was gradually reduced in the mice $\mathrm{PF}$, which is the only suture fusing in the first weeks after birth, and Axin2 elimination caused premature suture closure and craniosynostosis $(34,35)$. These research findings indicate that loss of suture MSCs which are capable of self-renewability, may lead to premature cranial suture fusion. Down-regulation of one or more of the above-mentioned genes may impair the stemness of suture MSCs and induce apoptosis through specific signaling pathways which 
needs further investigation.

In summary, we have successfully isolated, cultured and characterized the human cranial suture derived mesenchymal stem cells. Overexpression of osteogenic related genes and down-regulated stemness-related genes have been found in the MSCs derived from the prematurely fused sutures, which may lead to premature osteogenic differentiation and suppress self-renewal of stem cells ultimately resulting in craniosynostosis. Thus, we will strive to study the role of specific gene and related signaling pathway in maintaining suture MSCs stemness to further develop pharmacologic and genetic strategies, which in turn improves the current operative methods and prevents the prenatal craniosynostosis soon. Moreover, utilizing and altering osteogenic differentiation of suture MSCs could be a cell-based therapy for the treatment of critical skull bone defects when combined with biomaterial scaffolds in regenerative medicine.

\section{Acknowledgments}

This work was supported by Nanjing Medical Science and Technology Development Project (Grant number: YKK17163). The funders had no role in study design, data collection and analysis, decision to publish, or preparation of the manuscript.

\section{Potential Conflict of Interest}

The authors have no conflicting financial interest.

\section{Author Contributions}

Weimin Shen and Liangliang Kong conceived and designed the experiments. Liangliang Kong and Yuan Wang mainly performed the experiments. Yi Ji, Jianbing Chen and Weimin Shen analyzed the data. Liangliang Kong wrote the manuscript. Jianbing Chen and Jie Cui assisted with revising the manuscript.

\section{References}

1. Slater BJ, Lenton KA, Kwan MD, Gupta DM, Wan DC, Longaker MT. Cranial sutures: a brief review. Plast Reconstr Surg 2008;121:170e-178e

2. Twigg SR, Wilkie AO. A genetic-pathophysiological framework for craniosynostosis. Am J Hum Genet 2015;97:359377

3. Wilkie AO. Epidemiology and genetics of craniosynostosis. Am J Med Genet 2000;90:82-84

4. Forrest CR, Hopper RA. Craniofacial syndromes and surgery. Plast Reconstr Surg 2013;131:86e-109e

5. Kirmi O, Lo SJ, Johnson D, Anslow P. Craniosynostosis: a radiological and surgical perspective. Semin Ultrasound CT MR 2009;30:492-512

6. Hankinson TC, Fontana EJ, Anderson RC, Feldstein NA. Surgical treatment of single-suture craniosynostosis: an argument for quantitative methods to evaluate cosmetic outcomes. J Neurosurg Pediatr 2010;6:193-197

7. Wan DC, Kwan MD, Lorenz HP, Longaker MT. Current treatment of craniosynostosis and future therapeutic directions. Front Oral Biol 2008;12:209-230

8. Sahar DE, Longaker MT, Quarto N. Sox9 neural crest determinant gene controls patterning and closure of the posterior frontal cranial suture. Dev Biol 2005;280:344-361

9. Xu Y, Malladi P, Chiou M, Longaker MT. Isolation and characterization of posterofrontal/sagittal suture mesenchymal cells in vitro. Plast Reconstr Surg 2007;119:819-829

10. Nacamuli RP, Fong KD, Lenton KA, Song HM, Fang TD, Salim A, Longaker MT. Expression and possible mechanisms of regulation of BMP3 in rat cranial sutures. Plast Reconstr Surg 2005;116:1353-1362

11. Zhao H, Feng J, Ho TV, Grimes W, Urata M, Chai Y. The suture provides a niche for mesenchymal stem cells of craniofacial bones. Nat Cell Biol 2015;17:386-396

12. Maruyama T, Jeong J, Sheu TJ, Hsu W. Stem cells of the suture mesenchyme in craniofacial bone development, repair and regeneration. Nat Commun 2016;7:10526

13. Livak KJ, Schmittgen TD. Analysis of relative gene expression data using real-time quantitative PCR and the 2(-Delta Delta C(T)) Method. Methods 2001;25:402-408

14. Ni QF, Tian Y, Kong LL, Lu YT, Ding WZ, Kong LB. Latexin exhibits tumor suppressor potential in hepatocellular carcinoma. Oncol Rep 2014;31:1364-1372

15. Lemonnier J, Haÿ E, Delannoy P, Lomri A, Modrowski D, Caverzasio J, Marie PJ. Role of $\mathrm{N}$-cadherin and protein kinase $\mathrm{C}$ in osteoblast gene activation induced by the S252W fibroblast growth factor receptor 2 mutation in Apert craniosynostosis. J Bone Miner Res 2001;16:832-845

16. Buchanan EP, Xue AS, Hollier LH Jr. Craniofacial syndromes. Plast Reconstr Surg 2014;134:128e-153e

17. Sauvageau M, Sauvageau G. Polycomb group proteins: multi-faceted regulators of somatic stem cells and cancer. Cell Stem Cell 2010;7:299-313

18. Reya T, Morrison SJ, Clarke MF, Weissman IL. Stem cells, cancer, and cancer stem cells. Nature 2001;414:105-111

19. Otto AW. Lehrbuch der pathologischen Anatomie des Menschen und der Thiere/ 1. Berlin: Rücker; 1830.

20. Jiang T, Ge S, Shim YH, Zhang C, Cao D. Bone morphogenetic protein is required for fibroblast growth factor 2-dependent later-stage osteoblastic differentiation in cranial suture cells. Int J Clin Exp Pathol 2015;8:2946-2954

21. Rice DP. Developmental anatomy of craniofacial sutures. Front Oral Biol 2008;12:1-21

22. Heller JB, Gabbay JS, Wasson K, Mitchell S, Heller MM, Zuk P, Bradley JP. Cranial suture response to stress: expression patterns of Noggin and Runx2. Plast Reconstr Surg 2007;119:2037-2045

23. Park J, Park OJ, Yoon WJ, Kim HJ, Choi KY, Cho TJ, 
Ryoo HM. Functional characterization of a novel FGFR2 mutation, E731K, in craniosynostosis. J Cell Biochem 2012; 113:457-464

24. McGee-Lawrence ME, Li X, Bledsoe KL, Wu H, Hawse JR, Subramaniam M, Razidlo DF, Stensgard BA, Stein GS, van Wijnen AJ, Lian JB, Hsu W, Westendorf JJ. Runx2 protein represses Axin2 expression in osteoblasts and is required for craniosynostosis in Axin2-deficient mice. J Biol Chem 2013;288:5291-5302

25. Delezoide AL, Benoist-Lasselin C, Legeai-Mallet L, Le Merrer M, Munnich A, Vekemans M, Bonaventure J. Spatio-temporal expression of FGFR 1, 2 and 3 genes during human embryo-fetal ossification. Mech Dev 1998;77:1930

26. Greenwald JA, Mehrara BJ, Spector JA, Warren SM, Fagenholz PJ, Smith LE, Bouletreau PJ, Crisera FE, Ueno $\mathrm{H}$, Longaker MT. In vivo modulation of FGF biological activity alters cranial suture fate. Am J Pathol 2001;158:441452

27. Jung Y, Nolta JA. BMI1 regulation of self-renewal and multipotency in human mesenchymal stem cells. Curr Stem Cell Res Ther 2016;11:131-140

28. Alhadlaq A, Mao JJ. Mesenchymal stem cells: isolation and therapeutics. Stem Cells Dev 2004;13:436-448

29. Bhattacharya R, Mustafi SB, Street M, Dey A, Dwivedi SK. Bmi-1: at the crossroads of physiological and pathological biology. Genes Dis 2015;2:225-239
30. van der Lugt NM, Domen J, Linders K, van Roon M, Robanus-Maandag $\mathrm{E}$, te Riele $\mathrm{H}$, van der Valk $M$, Deschamps J, Sofroniew M, van Lohuizen M, Berns A. Posterior transformation, neurological abnormalities, and severe hematopoietic defects in mice with a targeted deletion of the bmi-1 proto-oncogene. Genes Dev 1994;8:757-769

31. Biehs B, Hu JK, Strauli NB, Sangiorgi E, Jung H, Heber RP, Ho S, Goodwin AF, Dasen JS, Capecchi MR, Klein OD. BMI1 represses Ink4a/Arf and Hox genes to regulate stem cells in the rodent incisor. Nat Cell Biol 2013;15:846852

32. Mitsui K, Tokuzawa Y, Itoh H, Segawa K, Murakami M, Takahashi K, Maruyama M, Maeda M, Yamanaka S. The homeoprotein Nanog is required for maintenance of pluripotency in mouse epiblast and ES cells. Cell 2003;113:631642

33. Xie X, Piao L, Cavey GS, Old M, Teknos TN, Mapp AK, Pan Q. Phosphorylation of Nanog is essential to regulate Bmil and promote tumorigenesis. Oncogene 2014;33:20402052

34. Maruyama T, Mirando AJ, Deng CX, Hsu W. The balance of WNT and FGF signaling influences mesenchymal stem cell fate during skeletal development. Sci Signal 2010;3:ra40

35. Yu HM, Jerchow B, Sheu TJ, Liu B, Costantini F, Puzas JE, Birchmeier W, Hsu W. The role of Axin2 in calvarial morphogenesis and craniosynostosis. Development 2005;132: 1995-2005 